\title{
CRIOCONSERVAÇÃO EM SEMENTES DE CEBOLA ${ }^{1}$
}

\author{
TATIANAFUENTES MOLINA² ${ }^{2}$ MARIAÂNGELAANDRÉ TILLMANN LUCIANABICCADODE $^{4}$, JUDITHVIÉGAS ${ }^{5}$
}

RESUMO - O presente trabalho teve como objetivo avaliar os efeitos de diferentes técnicas de crioconservação na qualidade fisiológica, composição química e índice mitótico de sementes de cebola. Sementes de cebola, cultivar Baia Periforme, foram expostas, durante uma hora, a duas técnicas de crioconservação: (a) sem e (b) com crioprotetor (glicerol 50\%), seguidas de três métodos de descongelamento: (1) temperatura ambiente de $25^{\circ} \mathrm{C}$, durante duas horas; (2) banho-maria a $37^{\circ} \mathrm{C}$, durante cinco minutos; (3) microondas em potência de $70 \mathrm{~W}$, durante cinco minutos. Antes e após a crioconservação, foram realizadas as seguintes avaliações: teor de água, germinação, vigor (envelhecimento acelerado, primeira contagem de germinação e comprimento de raiz e de parte aérea das plântulas), composição química (teor de açúcar solúvel, proteínas e amido), análise do ciclo celular e índice mitótico. A imersão em nitrogênio líquido, sem o uso de crioprotetor, é uma técnica adequada para a crioconservação de sementes de cebola, não altera a percentagem de germinação e a composição química das sementes, sendo também o tratamento que proporciona maior número de células em divisão celular após o descongelamento das sementes. O tratamento criogênico, com uso de glicerol $50 \%$ como crioprotetor, é prejudicial à qualidade físiológica e altera a composição química de sementes de cebola. O descongelamento das sementes em microondas é mais adequado do que em temperatura ambiente ou banho-maria, porém este último possibilita maior índice mitótico que os demais tratamentos.

Termos para indexação: Allium cepa, armazenamento, nitrogênio líquido, qualidade físiológica.

\section{CRYOCONSERVATION IN ONION SEEDS}

ABSTRACT - The present paper aimed to evaluate the effects in the physiological, chemical and cellular quality of cryopreserved seeds through different techniques. Onion seeds of the Baia Periforme cultivar were submitted, for one hour, to two cryopreservation techniques. (a) immersion in $\mathrm{N}_{2}$ fluid $\left(-196^{\circ} \mathrm{C}\right.$ ) with cryoprotector (glycerol $50 \%$ ) and (b) immersion in $\mathrm{N}_{2}$ fluid. After the cryogenization period of time, the seeds were submitted to three thawing methods: (1) room temperature of $25^{\circ} \mathrm{C}$ for two hours; (2) water bath (double-boiler) at $37^{\circ} \mathrm{C}$ for five minutes; (3) microwave the $70 \mathrm{~W}$ power for five minutes. Before and after the cryopreservation, the following parameters were assessed: water content, germination, vigour (accelerated aging, first counting, length of root and of the air parts of the plantules), chemical composition (soluble sugar, proteins and starch contents) and analysis of the cell cycle and mitotic index. The immersion in fluid nitrogen, without the use of cryoprotector, is an adequate technique for the cryopreservation of onion seeds that does not alter the germination nor the chemical composition of the seeds, and it was also the treatment that presented the highest number of cells in cell division of all of the melting methods. The cryogenic treatment with the use of glycerol $50 \%$ as cryoprotector damaged the physiological quality and altered the chemical composition of the onion seeds. The thawing of the seeds in the microwave is more adequate than thawing at room temperature or in a water bath. However, the last one presented higher mitotic rate than the other treatments.

Index terms: Allium cepa, storaged, $\mathrm{N}_{2}$ fluid, physiological quality.

\footnotetext{
${ }^{1}$ Submetido em 02/12/2005. Aceito para publicação em 12/06/2006. Parte da tese do primeiro autor apresentada a FAEM/UFPel;

${ }^{2}$ Bióloga, Dra.tmolina@pop.com.br;

${ }_{3}^{3}$ Prof. Adjunto, Dr., Departamento de Fitotecnia, FAEM/UFPel, Caixa Postal 354, 96010-900, Pelotas, RS. Bolsista de produtividade em
}

pesquisa do $\mathrm{CNPq}$

${ }^{4}$ Profa. Dra., Universidade Católica de Pelotas, CEP: 96015-960, PelotasRS;

${ }^{5}$ Prof. Adjunto, Dr., Departamento de Zoologia e Genética, IB/UFPel, Caixa Postal 354, CEP: 96010-900, Pelotas - RS. 


\section{INTRODUÇÃO}

$\mathrm{O}$ armazenamento em baixas temperaturas, o que inclui a crioconservação em nitrogênio líquido, é um método eficiente e prático para a conservação dos recursos fitogenéticos. Medeiros e Cavallar (1992) definem crioconservação em nitrogênio líquido como sendo a preservação de materiais biológicos a baixas temperaturas (entre -160 e $-196^{\circ} \mathrm{C}$ ), nas quais todos os processos metabólicos são essencialmente paralisados e mantidos em estado latente, proporcionando a preservação dos materiais a longo prazo. Outros autores acrescentam que a crioconservação em nitrogênio líquido é um método potencialmente estudado para reduzir a taxa de deterioração, aumentando assim o tempo de armazenamento das sementes, assegurando a preservação das fontes genéticas da planta, além de reduzir os custos e a perda da viabilidade (Stanwood e Bass, 1981; Stanwood, 1985).

De acordo com o Internacional Board for Plant Genetic Resources - IPBGR (1982), a crioconservação é uma técnica indicada para as espécies de propagação vegetativa, espécies com sementes recalcitrantes, germoplasmas raros ou mesmo espécies ameaçadas de extinção e espécies de plantas silvestres. Além disso, a conservação em nitrogênio líquido pode ser usada para espécies de sementes de importância agronômica (Stanwood, 1980, 1985 e 1987).

Todos os procedimentos de crioconservação requerem uma etapa de preparação da estrutura vegetal a ser conservada para a imersão em nitrogênio líquido. A preparação deve promover a desidratação do material para evitar a formação de cristais de gelo no interior da célula, o que é letal. A desidratação pode ser induzida por cristalização do meio externo durante uma fase lenta de resfriamento até atingir $30^{\circ} \mathrm{C} \mathrm{a}-40^{\circ} \mathrm{C}$. Transferindo-se rapidamente o material vegetal para o nitrogênio líquido, obtém-se a vitrificação da célula, isto é, os componentes celulares passam do estado líquido para sólido amorfo e meta-estável, evitando a formação de cristais de gelo no interior da célula, que podem causar ruptura das membranas resultando em colapso e morte, como consequência da perda da semipermeabilidade e da compartimentação celular (Salomão, 2002).

Uma alternativa importante para aplicação desta técnica é submeter o material a agentes crioprotetores, à base de dimetilsulfóxido (DMSO), glicerol, etileno glicol, metanol e propileno glicol, entre outros (Salomão, 2002). Entretanto, esses crioprotetores podem ser tóxicos ou causar estresse osmótico, levando as células à morte ou modificando sua resposta morfogenética em cultura (Sakai, 1995). Portanto, utilizam-se primeiramente soluções com baixas concentrações para que haja entrada dos componentes permeáveis na célula e, em seguida, soluções concentradas de crioprotetores para promover a vitrificação. Após esse procedimento, os frascos são transferidos para o nitrogênio líquido.

Os agentes crioprotetores penetrantes são substâncias ou fármacos que diminuem as lesões de origem química ou mecânica que o congelamento causa sobre a célula (Gonzalez, 2004).

Os crioprotetores agem reduzindo os danos celulares causados pelos efeitos da concentração dos sais no meio e possuem estruturas que lhes permitem fazer ligações de hidrogênio com a molécula de água, diminuindo assim a formação de cristais de gelo, não permitindo o aumento de tamanho desses cristais e diminuindo a concentração de soluto nos meios extra e intracelular. Estas ligações de hidrogênio também promovem a estabilização da estrutura quaternária das proteínas de membrana, preservando-as da desidratação. $\mathrm{O}$ uso de crioprotetores para os quais as células têm alta permeabilidade resulta em boa sobrevivência celular (Gonzalez, 2004).

Em um banco de germoplasma a baixas temperaturas, não só o processo de crioconservação deve ser levado em consideração como também o método de descongelamento, pois quanto mais rápido ocorrer o descongelamento das sementes, melhor a preservação de suas características fisiológicas. Portanto, o método de descongelamento a temperatura ambiente se torna questionável, uma vez que existe a possibilidade do recongelamento durante este período, necessitando, desta forma, estudos em relação aos métodos mais rápidos como o descongelamento em banho-maria (temperatura de $40^{\circ} \mathrm{C}$ ) e a utilização do microondas.

Considerando que as sementes de cebola perdem rapidamente a viabilidade pós-colheita e por apresentarem alto valor comercial, o presente trabalho teve como objetivo avaliar os efeitos de diferentes técnicas de crioconservação na qualidade fisiológica, composição química e índice mitótico de sementes de cebola.

\section{MATERIAL E MÉTODOS}

Neste trabalho, foram utilizadas sementes de cebola (Allium cepa L.), cv. Baia Periforme, de procedência nacional, cedidas pela Feltrin - Importadora de Sementes Ltda.

\section{Crioconservação das sementes}

Para a crioconservação, as sementes foram colocadas 
em tubos cilíndricos e crioconservadas em botijões criogênicos durante o período de uma hora, a $-196^{\circ} \mathrm{C}$.

As técnicas de crioconservação foram imersão em nitrogênio líquido com crioprotetor (glicerol 50\%) e imersão em nitrogênio líquido sem o uso de crioprotetor. A testemunha não foi imersa em nitrogênio líquido.

\section{Descongelamento das sementes}

Após o tratamento criogênico, as sementes foram descongeladas através dos métodos: descongelamento lento, a temperatura ambiente de $25^{\circ} \mathrm{C}$ durante duas horas; descongelamento em banho-maria, a temperatura de $37^{\circ} \mathrm{C}$ durante cinco minutos; descongelamento em microondas, a uma potência de $70 \mathrm{~W}$ durante cinco minutos.

Após o descongelamento, as sementes foram lavadas com água destilada.

\section{Caracterização fisiológica das sementes}

Antes e após o tratamento criogênico, as sementes foram avaliadas através dos seguintes parâmetros: teor de água, germinação, vigor (envelhecimento acelerado, primeira contagem de germinação e comprimento de raiz e da parte aérea), composição química e análise do ciclo celular e índice mitótico.

$\mathrm{O}$ teor de água das sementes foi determinado em três subamostras pelo método da estufa a $105 \pm 3^{\circ} \mathrm{C}$, por 24 horas, conforme as Regras para Análise de Sementes (Brasil, 1992). Os resultados foram expressos em percentagem.

Para o teste de germinação, foram utilizadas 200 sementes, distribuídas em quatro repetições iguais, sobre duas folhas de papel mata-borrão previamente umedecidas com água destilada e mantidas em germinador a temperatura de $20^{\circ} \mathrm{C}$. As avaliações foram realizadas no sexto e décimo segundo dia após a semeadura, de acordo com as Regras para Análise de Sementes (Brasil, 1992). Os resultados foram expressos em porcentagem de plântulas normais.

A primeira contagem de germinação constou da avaliação do número de plântulas normais obtidas no sexto dia após a instalação do teste de germinação, expressa em percentagem.

Para a determinação do comprimento da raiz e da parte aérea, foram utilizadas 150 sementes, distribuídas em três repetições iguais e colocadas para germinar em papel germitest, umedecido com água destilada, na quantidade de 2,5 vezes a sua massa. As sementes foram distribuídas sobre uma linha horizontal traçada no terço superior do papel umedecido. Os rolos contendo as sementes permaneceram no germinador por seis dias a $20^{\circ} \mathrm{C}$, quando então foi procedida a avaliação. Os resultados foram expressos em centímetros.

Para o teste de envelhecimento acelerado das sementes, foram utilizadas caixas plásticas (tipo gerbox), possuindo em seu interior uma bandeja com tela de alumínio onde as sementes foram distribuídas de maneira a formarem camada uniforme. Em cada caixa, foram adicionados $40 \mathrm{~mL}$ de água destilada; as caixas, tampadas, foram mantidas em câmara tipo BOD, a $42^{\circ} \mathrm{C}$ por 72 horas com umidade relativa próxima a $100 \%$ (AOSA, 1983). Após o envelhecimento, as sementes foram submetidas ao teste de germinação, conforme descrito anteriormente. Os resultados obtidos foram expressos em percentagem de plântulas normais.

\section{Composição química}

Após o descongelamento, as sementes, acondicionadas em envelopes, foram mantidas em estufa a $70^{\circ} \mathrm{C}$, durante 48 horas e, posteriormente, colocadas em dessecador. As sementes foram moídas e guardadas em câmara fria a $-18^{\circ} \mathrm{C}$, durante quatro meses, até a determinação das avaliações bioquímicas.

Os efeitos da crioconservação sobre os teores de amido, açúcar solúvel e proteínas foram determinados em quatro subamostras de 0,25 gramas de sementes moídas. Os teores de açúcar solúvel foram determinados através das reações com antrona (Clegg, 1956). As determinações do teor de amido foram realizadas com o resíduo dos centrifugados, após a extração do açúcar solúvel, segundo o método descrito por McCready et al. (1950). As proteínas solúveis foram determinadas pela metodologia descrita por Bradford (1976).

As determinações dos teores de amido e açúcar solúvel foram realizadas em espectofotômetro a $620 \mathrm{~nm}$ e de proteína, a $595 \mathrm{~nm}$. Os resultados foram expressos em $\mu \mathrm{g} . \mathrm{g}^{-1} \mathrm{de}$ semente.

\section{Análise do ciclo celular e índice mitótico}

Para avaliar a freqüência de divisão celular através do índice mitótico, as sementes foram colocadas para germinar, conforme metodologia descrita anteriormente. No sexto dia de semeadura, entre 8 e 10 horas da manhã, foi realizada a coleta do ápice radicular das plântulas normais, quando as mesmas apresentavam, aproximadamente, $1,5 \mathrm{~cm}$ de comprimento, as raízes foram colocadas diretamente no fixador Carnoy ( 3 partes de álcool etílico absoluto : 1 parte de ácido acético glacial), por 24 horas, à temperatura ambiente. Posteriormente, as raízes foram lavadas em água corrente, transferidas para álcool $70 \%$ e estocadas em freezer, até a preparação das lâminas.

No preparo das lâminas do ápice radicular, estas foram lavadas duas vezes em água destilada e hidrolizadas em $\mathrm{HCl}$ $5 \mathrm{~N}$, por 10 minutos, à temperatura ambiente e, novamente, lavadas com água destilada.

Com o auxílio do microscópio estereoscópio, as zonas 
meristemáticas das raízes foram coletadas e transferidas para lâmina na qual foi adicionado ácido acético $45 \%$ para o esmagamento do material. A lamínula foi colocada e o material aquecido e prensado.

Posteriormente, as lâminas foram colocadas dentro de tubos cilíndricos com nitrogênio líquido $\left(\mathrm{N}_{2} \mathrm{~L}\right)$, a uma temperatura de $-196^{\circ} \mathrm{C}$, de forma que ficassem imersas no mesmo, para a retirada da lamínula e fixação do material na lâmina. Após, a lâmina foi lavada e seca ao ar. A coloração foi realizada por imersão em solução de Giemsa 2\%, pH 6,8, por cinco minutos.

A observação do material foi realizada em microscópio ótico, a uma magnitude de 400X. Para a contagem das células em divisão celular, adotou-se o método de varredura, partindo do canto inferior da lâmina, da esquerda para a direita. Foram contadas as células em divisão mitótica e em intérfase, num total de 100 células por lâmina. A unidade experimental constou de quatro lâminas por repetição. Assim, foram analisadas 400 células por repetição, de três repetições por tratamento, num total de 1.200 células por tratamento. $\mathrm{O}$ indice mitótico foi calculado como a percentagem de células em divisão (prófase, pró-metáfase, metáfase, anáfase e telófase) do total de células observadas.

\section{Análise estatística}

O delineamento experimental foi inteiramente casualizado, em arranjo fatorial $(2 \times 3+1)$, ou seja, duas técnicas de crioconservação e três métodos de descongelamento + testemunha, com três repetições.

As análises de variância e as comparações de médias pelo teste de Duncan ao nível de 5\% de significância foram procedidas com o auxílio do programa computacional SANEST - Sistema de Análise Estatística (Zonta e Machado, 1984).

\section{RESULTADOS E DISCUSSÃO}

Qualidade fisiológica das sementes de cebola submetidas a diferentes técnicas de crioconservação.

Na Tabela 1, são apresentados os resultados da qualidade fisiológica de sementes de cebola submetidas a diferentes técnicas de crioconservação. Verificou-se que as sementes submetidas ao tratamento criogênico, sem crioprotetor, apresentaram germinação e vigor (Envelhecimento Acelerado e Primeira Contagem) superior àquelas com uso de crioprotetor. O comprimento de raiz e da parte aérea das plântulas não foram afetados pela crioconservação.

As sementes de cebola imersas em nitrogênio líquido, sem o uso de crioprotetor, mantiveram sua qualidade, não diferindo da testemunha em todos os parâmetros avaliados. Estes resultados confirmam os obtidos por Stanwood e Sowa (1995), ao armazenarem 14 variedades de cebola, nas temperaturas de $5,-18$ e $-196^{\circ} \mathrm{C}$, durante um período de 10 anos e constatarem que a germinação média das sementes mantidas a -18 e $-196^{\circ} \mathrm{C}$ não declinou ao longo do tempo, ficando em torno de $92 \%$, enquanto a germinação de sementes armazenadas a $5^{\circ} \mathrm{C}$ diminuiu de 94 para $68 \%$.

Entretanto, as sementes crioconservadas com o uso de crioprotetor (glicerol 50\%) apresentaram um decréscimo acentuado na germinação (22 pontos percentuais), envelhecimento acelerado (66 pontos percentuais) e na primeira contagem (46 pontos percentuais). Esses resultados não estão de acordo com os obtidos com sementes de orégano, cujas sementes crioconservadas, sob ação do glicerol como crioprotetor, apresentaram valores de germinação superiores àquelas submetidas ao nitrogênio sem glicerol, indicando a necessidade do uso do glicerol como crioprotetor para conservação destas sementes (Vargas et al., 2004).

Qualidade fisiológica das sementes de cebola após diferentes métodos de descongelamento.

Observa-se na Tabela 2, que na crioconservação, sem crioprotetor, o teor de água das sementes foi mantido após o descongelamento independentemente do método utilizado, não diferindo da testemunha. Já na técnica de crioconservação, com crioprotetor, houve um aumento de 42 pontos percentuais no teor de água das sementes após os três métodos de descongelamento, evidenciando que o glicerol $50 \%$, utilizado como crioprotetor, aumentou acentuadamente o teor de água das sementes. Quimicamente, o glicerol é um álcool que contém três grupos funcionais de hidroxila que podem aceitar um hidrogênio da molécula de água em seis sítios diferentes

TABELA 1. Qualidade das sementes de cebola submetidas a diferentes técnicas de crioconservação, quanto à germinação $(G)$, envelhecimento acelerado (EA), primeira contagem (PC), comprimento de raiz (CR) e comprimento de parte aérea (CPA).

\begin{tabular}{lccccc}
\hline Técnicas de crioconservação & $\begin{array}{c}\text { G } \\
(\%)\end{array}$ & $\begin{array}{c}\text { EA } \\
(\%)\end{array}$ & $\begin{array}{c}\text { PC } \\
(\%)\end{array}$ & $\begin{array}{c}\text { CR } \\
(\mathrm{cm})\end{array}$ & $\begin{array}{c}\text { CPA } \\
(\mathrm{cm})\end{array}$ \\
\hline Sem crioprotetor & 93 a & 89 a & 76 a & 1,6 a & 1,4 a \\
Com crioprotetor (glicerol 50\%) & 70 b & 27 b & 39 b & 1,7 a & 1,4 a \\
Testemunha & 92 a & 93 a & 85 a & 2,1 a & 1,8 a \\
\hline CV $(\%)$ & 4,67 & 7,01 & 5,39 & 12,61 & 11,54 \\
\hline
\end{tabular}

Médias seguidas por letras distintas, na coluna, diferem entre si ao nível de $5 \%$ de probabilidade pelo teste de Duncan. 
TABELA2. Qualidade das sementes de cebola crioconservadas e submetidas a diferentes métodos de descongelamento, quanto ao teor de água (TA), germinação (G), envelhecimento acelerado (EA), primeira contagem (PC), comprimento de raiz (CR) e comprimento da parte aérea (CPA).

\begin{tabular}{lccccccc}
\hline Técnicas de crioconservação & $\begin{array}{c}\text { Métodos de } \\
\text { descongelamento }\end{array}$ & $\begin{array}{c}\text { TA } \\
(\%)\end{array}$ & $\begin{array}{c}\mathrm{G} \\
(\%)\end{array}$ & $\begin{array}{c}\text { EA } \\
(\%)\end{array}$ & $\begin{array}{c}\text { PC } \\
(\%)\end{array}$ & $\begin{array}{c}\text { CR } \\
(\mathrm{cm})\end{array}$ & $\begin{array}{c}\text { CPA } \\
(\mathrm{cm})\end{array}$ \\
\hline & Ambiente & $7,4 \mathrm{a}$ & $93 \mathrm{a}$ & $84 \mathrm{~b}$ & $74 \mathrm{~b}$ & $1,3 \mathrm{~b}$ & $1,1 \mathrm{c}$ \\
& Banho-maria & $7,2 \mathrm{a}$ & $94 \mathrm{a}$ & $88 \mathrm{ab}$ & $75 \mathrm{~b}$ & $1,4 \mathrm{~b}$ & $1,3 \mathrm{~b}$ \\
Sem crioprotetor & Microondas & $7,4 \mathrm{a}$ & $93 \mathrm{a}$ & $90 \mathrm{ab}$ & $71 \mathrm{~b}$ & $1,4 \mathrm{~b}$ & $1,2 \mathrm{c}$ \\
& Testemunha & $7,5 \mathrm{a}$ & $92 \mathrm{a}$ & $93 \mathrm{a}$ & $85 \mathrm{a}$ & $2,1 \mathrm{a}$ & $1,8 \mathrm{a}$ \\
\hline & Ambiente & $49,6 \mathrm{a}$ & $50 \mathrm{c}$ & $9 \mathrm{~b}$ & $9 \mathrm{c}$ & $1,8 \mathrm{~b}$ & $1,1 \mathrm{c}$ \\
Com crioprotetor & Banho-maria & $49,2 \mathrm{a}$ & $67 \mathrm{~b}$ & $6 \mathrm{~b}$ & $35 \mathrm{~b}$ & $1,5 \mathrm{~b}$ & $1,5 \mathrm{~b}$ \\
(glicerol 50\%) & Microondas & $49,6 \mathrm{a}$ & $64 \mathrm{~b}$ & $11 \mathrm{~b}$ & $31 \mathrm{~b}$ & $1,4 \mathrm{~b}$ & $1,1 \mathrm{c}$ \\
& Testemunha & $7,5 \mathrm{~b}$ & $92 \mathrm{a}$ & $93 \mathrm{a}$ & $85 \mathrm{a}$ & $2,1 \mathrm{a}$ & $1,8 \mathrm{a}$ \\
\hline $\mathrm{CV}(\%)$ & & 1,77 & 4,67 & 7,01 & 5,39 & 12,62 & 11,54 \\
\hline
\end{tabular}

Médias seguidas por letras distintas, na coluna, diferem entre si ao nível de 5\% de probabilidade pelo teste de Duncan.

(Gonzalez, 2004). O glicerol 50\% pode ser utilizado para reduzir o dano físico e favorecer o processo de vitrificação durante a etapa de congelamento a temperaturas ultrabaixas, entretanto é importante observar o comportamento das sementes de diferentes espécies em presença deste crioprotetor.

Na presente pesquisa, as sementes crioconservadas, com uso de crioprotetor, apresentaram média de teor de água de 49,5\%. Provavelmente, este alto teor de água contribuiu para a redução da qualidade físiológica das sementes. O teor de água das sementes é um dos principais fatores controladores da crioconservação. Existe um nível máximo de umidade para o congelamento (High Moisture Freezing Limit - NMU) acima do qual a viabilidade da semente é reduzida (Stanwood, 1985). Este limite crítico é, em geral, uma faixa relativamente estreita de umidade para cada espécie, mas pode variar entre espécies.

Diversos pesquisadores mostraram a importância do teor de água das sementes na crioconservação. Ao crioconservarem sementes recalcitrantes de chá (Camellia sinensis (L) O. Kuntze) e de jaca (Artocarpus heterophyllus Lamk.), Chandel et al. (1995) constataram que o teor de água adequado para crioconservação foi de $14 \%$ e que acima desse valor as sementes perderam sua capacidade germinativa. Sementes de alface foram danificadas ao serem crioconservadas com mais de 18\% de umidade (Roos e Stanwood, 1981). Resultados semelhantes foram obtidos na crioconservação de sementes de Sesamum indicum, com 12\% de umidade (Stanwood, 1987).

O estresse de congelamento, com o uso de crioprotetor, pode ter causado a interrupção e desestruturação de alguns processos metabólicos assim como reportados por Fleck et al. (1999) e Dumet e Benson (2000) com outros sistemas biológicos. Alguns crioprotetores podem ser tóxicos ou podem causar estresse osmótico, levando à morte das células ou modificando sua resposta morfogenética em cultura (Sakai, 1995). Também, é possível que os danos observados na crioconservação possam ter sido causados pela perda da integridade celular devido à formação de cristais de gelo e ao emprego do crioprotetor, que pode danificar membranas, conforme descrito no trabalho realizado por Martínez-Montero et al. (2002).

As sementes crioconservadas, com o uso de crioprotetor, e descongeladas pelas diferentes metodologias utilizadas, apresentaram decréscimo acentuado na qualidade fisiológica, de acordo com todos os parâmetros avaliados. A redução na germinação foi em média de 32 pontos percentuais. Para os parâmetros de vigor analisados, as diminuições de qualidade também foram acentuadas, evidenciando que a crioconservação, com uso de crioprotetor, não foi adequada para sementes de cebola. Também, foi observada por Stonayova (1994), redução na viabilidade de sementes de milho crioconservadas por um período de 10 anos.

Por outro lado, as sementes quando crioconservadas, sem o uso de crioprotetor, apresentaram valores de germinação iguais ou superiores a 92\%, para todos os métodos de descongelamento estudados, não diferindo em relação à testemunha, embora tenha ocorrido redução no vigor para todos os métodos de descongelamento.

Os resultados obtidos mostram que o descongelamento em ambiente foi o que mais prejudicou a qualidade das sementes, com ou sem uso de crioprotetor. As técnicas de descongelamento por banho-maria e microondas, não 
apresentaram diferenças entre si, para a maioria dos parâmetros de qualidade avaliados. Esses resultados confirmam a afirmativa de Pita Villamil (1997) de que os métodos mais rápidos de descongelamento se adaptam melhor a crioconservação, pois métodos lentos possibilitam o recongelamento das sementes. Há controvérsias quanto à velocidade de descongelamento adequada para garantir a integridade do material quando exposto ao nitrogênio líquido. Stawood e Bass (1981) indicam o descongelamento lento para evitar danos aos tecidos e células da semente.

Um parâmetro importante que deve ser observado para cada procedimento de crioconservação é o período em que o material pode ser conservado de tal forma que, quando avaliado, mostre pelo menos $60 \%$ de sobrevivência (Van den Houve et al., 1995, citado por Vieira, 2000). Os resultados apresentados nesta pesquisa mostram que a crioconservação, sem uso de crioprotetor, manteve a germinação das sementes de cebola. Estes resultados são promissores e demostram que sementes de cebola podem ser crioconservadas, com relativa eficiência, se, conforme Diniz (1999), forem estudados alguns parâmetros como: teor de água mais adequado, técnicas de congelamento e métodos de descongelamento.

\section{Composição química}

$\mathrm{Na}$ Tabela 3, encontram-se os valores da composição química - amido, proteína e açúcar solúvel das sementes de cebola submetidas às diferentes técnicas de crioconservação.

Observa-se que a técnica de crioconservação, sem o uso de crioprotetor, não alterou a composição química das sementes de cebola, ou seja, manteve os teores de amido, proteína e açúcar solúvel, não diferindo da testemunha. Entretanto as sementes crioconservadas, com o uso de crioprotetor (glicerol 50\%), apresentaram menores teores de proteína e açúcar solúvel indicando inibição da atividade

TABELA 3. Composição química das sementes de cebola submetidas a diferentes técnicas de crioconservação, quanto ao teor de amido (TAm), teor de proteína (TP) e teor de açúcar solúvel (TAS).

\begin{tabular}{lccc}
\hline Técnicas de crioconservação & $\begin{array}{c}\text { TAm } \\
(\mu \mathrm{g} . \mathrm{g}\end{array}$ & $\begin{array}{c}\text { TP } \\
\text { de semente }\end{array}$ & $\begin{array}{c}\text { TAS } \\
\text { Sem crioprotetor }\end{array}$ \\
\hline Com crioprotetor (glicerol 50\%) & 1607,1 a & 40,3 a & 37,8 a \\
Testemunha & 1742,7 a & 20,6 b & 24,0 b \\
\hline CV $(\%)$ & 16,8 & 9,0 & 12,8 \\
\hline
\end{tabular}

Médias seguidas por letras distintas, na coluna, diferem entre si ao nível de $5 \%$ de probabilidade pelo teste de Duncan. metabólica, provavelmente, devido ao aumento no teor de água das sementes pelo crioprotetor, capaz de promover danos às membranas celulares e ainda possivelmente à toxicidade do glicerol (Stanwood, 1985). Apesar de o glicerol ser o crioprotetor mais utilizado no congelamento de sêmem de espécies domésticas, seus efeitos deletérios sobre os espermatozóides ocorrem, provavelmente, pelas alterações causadas na membrana plasmática (Soares et al., 2002). Caso seja necessário o uso de crioprotetores para viabilizar o processo de crioconservação, deverá haver um esforço para dimuinuir a toxicidade do crioprotetor utilizando-se diferentes grupos químicos, concentrações e ainda adequando o tempo de exposição. Entretanto, estudando os efeitos do glicerol na viabilidade de micélio de fungos, foi observado que não houve influência do contato com o crioprotetor na recuperação dos mesmos (Herrera et al., 1998).

Esses resultados evidenciam que a técnica de crioconservação, sem o uso do crioprotetor, foi adequada para sementes de cebola, não alterando a composição química nem a germinação das sementes. Na preservação de materiais biológicos a baixas temperaturas (entre $-160 \mathrm{e}-196^{\circ} \mathrm{C}$ ), todos os processos metabólicos são essencialmente paralisados e mantidos em estado latente, proporcionando, conseqüentemente, preservação indefinida (Medeiros e Cavallar, 1992).

Na Tabela 4, são apresentados os valores da composição química (amido, proteína e açúcar solúvel) das sementes de cebola submetidas a diferentes métodos de descongelamento.

Os resultados confirmam os obtidos na avaliação da qualidade fisiológica, em que o tratamento criogênico, com o uso de crioprotetor (glicerol 50\%), não foi adequado para as sementes de cebola. Todos os métodos de descongelamento alteraram o teor de proteína e açúcar solúvel das sementes.

Observa-se que, sem o uso de crioprotetor, não houve diferença no teor de amido das sementes independentemente do método de descongelamento utilizado; o teor de açúcar solúvel, também, não foi alterado, quando o descogelamento foi realizado em banho-maria e microondas. Já o teor de proteína se manteve somente quando o descongelamento foi realizado em microondas.

Considerando que a composição química das sementes não deve ser alterada durante a crioconservação, o descongelamento em microondas foi o mais adequado, pois manteve inalterado o teor de amido, proteína e açúcar solúvel. Esses resultados confirmam que, quanto mais rápido e uniformemente ocorrer o descongelamento das sementes, melhor a preservação de suas características fisiológicas. Logo, 
TABELA 4. Composição química de sementes de cebola crioconservadas e submetidas a diferentes métodos de descongelamento, quanto ao teor de amido (TAm), teor de proteína (TP) e teor de açúcar solúvel (TAS).

\begin{tabular}{lcccc}
\hline \multirow{2}{*}{ Técnicas de crioconservação } & Métodos de & TAm & TP & TAS \\
\cline { 2 - 5 } & descongelamento & & $\left(\mu\right.$ g.g de semente $\left.{ }^{-1}\right)$ \\
\hline \multirow{3}{*}{ Sem crioprotetor } & Ambiente & $1522,9 \mathrm{a}$ & $40,9 \mathrm{ab}$ & $30,2 \mathrm{~b}$ \\
& Banho-maria & $1297,5 \mathrm{a}$ & $44,9 \mathrm{a}$ & $40,6 \mathrm{a}$ \\
& Microondas & $1812,0 \mathrm{a}$ & $39,8 \mathrm{bc}$ & $41,6 \mathrm{a}$ \\
& Testemunha & $1796,1 \mathrm{a}$ & $35,8 \mathrm{c}$ & $38,6 \mathrm{a}$ \\
\hline & Ambiente & $2497,5 \mathrm{a}$ & $16,2 \mathrm{bc}$ & $19,7 \mathrm{~b}$ \\
Com crioprotetor & Banho-maria & $2227,5 \mathrm{ab}$ & $18,3 \mathrm{~b}$ & $17,9 \mathrm{~b}$ \\
& Microondas & $1929,5 \mathrm{~b}$ & $12,0 \mathrm{c}$ & $19,8 \mathrm{~b}$ \\
\hline $\mathrm{CV}(\%)$ & Testemunha & $1796,1 \mathrm{~b}$ & $35,8 \mathrm{a}$ & $38,6 \mathrm{a}$ \\
\hline
\end{tabular}

Médias seguidas por letras distintas, na coluna, diferem entre si ao nível de 5\% de probabilidade pelo teste de Duncan.

o método de descongelamento lento (temperatura ambiente) se torna questionável, uma vez que existe a possibilidade do recongelamento durante este período. As etapas de secagem, acondicionamento e congelamento empregadas nas técnicas de crioconservação são importantes e devem ser ajustadas. Porém, a adequação da forma de descongelamento tem sido a etapa limitante no processo.

Com base nas informações obtidas neste estudo constatase que o tratamento criogênico, sem uso de crioprotetor, é uma técnica adequada para a crioconservação de sementes de cebola, pois não altera a germinação e composição química das sementes. Também é possível afirmar que o descongelamento em microondas é o mais adequado.

\section{Ciclo celular e índice mitótico}

As estimativas da frequência de células nas diferentes fases do ciclo celular, que são a interfase e a divisão celular (prófase, prometáfase, metáfase, anáfase e telófase), ocorrentes no meristema do ápice radicular de sementes de cebola crioconservadas, estão apresentadas na Tabela 5 .

Ao serem comparadas cada uma das diversas fases do ciclo celular após cada tipo de descongelamento, em cada técnica de crioconservação, verificou-se que as sementes crioconservadas, sem o uso do crioprotetor, não diferiram daquelas crioconservadas com glicerol $50 \%$, com exceção das fases de interfase e de prófase descongeladas tanto em banho-maria quanto em microondas.

Em todas as técnicas de crioconservação, a maior freqüência foi de células interfásicas, comparativamente às fases da divisão celular, variando na técnica de crioconservação, sem o uso de crioprotetor, de $72,59 \%$ (banho-maria) a $88,36 \%$ (testemunha), apresentando uma freqüência média de $81,83 \%$, conforme a Tabela 5 . Já com o uso do crioprotetor, a frequência de células em interfase variou de $81,64 \%$ (ambiente) a $88,36 \%$ (testemunha), apresentando uma frequência média de $86,19 \%$.

Esta maior freqüência de células interfásicas é esperada, pelo fato da interfase ser a fase mais longa do ciclo celular na maioria das células de organismos eucariotos. O ciclo celular das células somáticas está dividido em duas fases: a interfase e a divisão celular ou mitose. A interfase é constituída pelas fases G1 (crescimento celular), S (duplicação dos cromossomos) e G2 (preparo para a divisão celular). A mitose, que produz duas células filhas, é habitualmente seguida pela citocinese (separação das células filhas), e está constituída pelas fases de prófase, prometáfase, metáfase, anáfase e telófase. Estes períodos têm durações diversas de acordo com a célula e/ou organismo estudado. O ciclo celular de uma célula de ponta de raiz de cebola é de cerca de 17,40 horas (Vant' Hof, 1965, citado por Singh, 2003). O ciclo celular da Vicia faba é de cerca de 20 horas, das quais apenas $10 \%$ é dispendido pela mitose, sendo os períodos G1, S e G2 da interfase responsáveis por 25, 40 e $25 \%$, respectivamente (Viégas, 2004). Excetuam-se algumas fases da embriogênese em que, nas primeiras divisões do zigoto, as fases G1 e G2 da interfase são suprimidas, diminuindo drasticamente o tamanho da interfase (Cooper, 2001; Alberts et al., 2002).

Ao se utilizar o índice mitótico para comparar as técnicas de crioconservação, verifica-se que as mesmas diferem entre si. A técnica de crioconservação, sem o uso de crioprotetor, apresentou índice mitótico médio igual $18,17 \%$, enquanto que com crioprotetor apresentou índice mitótico médio de 13,81\% (Tabela 5).

Médias seguidas por asteriscos na coluna, diferem entre si ao nível de 5\% de probabilidade pelo teste de Duncan.

Resultados semelhantes foram encontrados por Sebaje 
TABELA 5. Freqüência de células do ápice radicular de sementes de cebola crioconservadas e submetidas a diferentes métodos de descongelamento em seis fases do ciclo celular: Interfase (I), Prófase (P), Pró-metáfase (Pm), Metáfase (M), Anáfase (A) e Telófase (T).

\begin{tabular}{|c|c|c|c|c|c|c|c|c|}
\hline \multirow{3}{*}{$\begin{array}{l}\text { Técnicas de } \\
\text { crioconservação }\end{array}$} & \multirow{3}{*}{$\begin{array}{c}\text { Métodos de } \\
\text { descongelamento }\end{array}$} & \multicolumn{6}{|c|}{ Ciclo Celular } & \multirow{3}{*}{$\begin{array}{c}\text { Índice } \\
\text { Mitótico } \\
\text { (\% células) }\end{array}$} \\
\hline & & \multirow{2}{*}{$\begin{array}{l}\text { Interfase } \\
(\% \text { células })\end{array}$} & \multicolumn{5}{|c|}{$\begin{array}{c}\text { Fases de divisão celular } \\
(\% \text { células })\end{array}$} & \\
\hline & & & $\mathrm{P}$ & $\mathrm{Pm}$ & $\mathrm{M}$ & $\mathrm{A}$ & $\mathrm{T}$ & \\
\hline \multirow{4}{*}{ Sem crioprotetor } & Ambiente & $83,22 \mathrm{bA}$ & $11,15 \mathrm{bB}$ & $4,04 \mathrm{aC}$ & $0,41 \mathrm{aD}$ & $0,55 \mathrm{abD}$ & $0,58 \mathrm{bD}$ & $16,78 \mathrm{~b}$ \\
\hline & Banho & $72,59 \mathrm{cA}$ & $22,31 \mathrm{aB}$ & $1,71 \mathrm{abC}$ & $0,99 \mathrm{aC}$ & $0,91 \mathrm{abC}$ & $1,33 \mathrm{abC}$ & $27,40 \mathrm{a}$ \\
\hline & Microondas & $81,84 \mathrm{bA}$ & $14,34 \mathrm{bB}$ & $0,80 \mathrm{bCD}$ & $0,75 \mathrm{aCD}$ & $0,25 \mathrm{bD}$ & $1,65 \mathrm{abC}$ & $18,16 \mathrm{~b}$ \\
\hline & Teste & $88,36 \mathrm{aA}$ & $4,06 \mathrm{cB}$ & $1,77 \mathrm{abBC}$ & $1,06 \mathrm{aC}$ & $1,85 \mathrm{aBC}$ & $2,38 \mathrm{aBC}$ & $11,64 \mathrm{~b}$ \\
\hline Freqüência média (\%) & & $81,83 \mathrm{~A}$ & $12,14 \mathrm{~B}$ & $1,93 \mathrm{C}$ & $0,78 \mathrm{D}$ & $0,79 \mathrm{D}$ & $1,41 \mathrm{CD}$ & $18,17^{*}$ \\
\hline \multirow{4}{*}{$\begin{array}{l}\text { Com crioprotetor } \\
\text { (glicerol 50\%) }\end{array}$} & $\mathrm{Amb}$ & $81,64 \mathrm{bA}$ & $12,99 \mathrm{aB}$ & $3,00 \mathrm{aC}$ & $0,62 \mathrm{aD}$ & $0,65 \mathrm{abD}$ & $0,76 \mathrm{aD}$ & $18,36 \mathrm{a}$ \\
\hline & Banho-maria & $86,28 \mathrm{abA}$ & $10,37 \mathrm{abB}$ & $1,26 \mathrm{aC}$ & $0,62 \mathrm{aC}$ & $0,25 \mathrm{bC}$ & $1,03 \mathrm{aC}$ & $13,72 \mathrm{a}$ \\
\hline & Mic & $88,08 \mathrm{aA}$ & $7,77 \mathrm{bB}$ & $1,51 \mathrm{aC}$ & $0,11 \mathrm{aD}$ & $0,55 \mathrm{abCD}$ & $1,29 \mathrm{aC}$ & $11,92 \mathrm{a}$ \\
\hline & Test & $88,36 \mathrm{aA}$ & $4,06 \mathrm{cB}$ & $1,77 \mathrm{aBC}$ & $1,06 \mathrm{aC}$ & $1,85 \mathrm{aBC}$ & $2,38 \mathrm{aBC}$ & $11,64 \mathrm{a}$ \\
\hline Freqüência média (\%) & & $86,19 \mathrm{~A}$ & $8,48 \mathrm{~B}$ & $1,84 \mathrm{C}$ & $0,54 \mathrm{E}$ & $0,73 \mathrm{DE}$ & $1,30 \mathrm{CD}$ & $13,81 * *$ \\
\hline
\end{tabular}

Médias seguidas por letras distintas, minúsculas nas colunas e maiúsculas nas linhas, diferem entre si ao nível de 5\% de probabilidade pelo teste de Duncan. Médias seguidas por asteriscos na coluna, diferem entre si ao nível de 5\% de probabilidade pelo teste de Duncan.

et al. (2003), ao analisarem a instabilidade cromossômica de arruda crioconservadas. Estes autores encontraram índice mitótico igual a $2,8 \%$ na testemunha. Já as raízes crioconservadas sem crioprotetor, apresentaram índice mitótico de 5,0\%, enquanto que a crioconservação associada ao uso de crioprotetor (glicerol) levou à diminuição do índice mitótico $(1,2 \%)$.

A freqüência de células em divisão aponta para um tecido em franco crescimento, como é o esperado em meristemas vegetais, tais como os das raízes primárias. Estes tecidos apresentam maior ou menor suscetibilidade a diversos estresses bióticos ou abióticos, indicando tanto a toxicidade de uma determinada substância, quanto o nível de reação em função de um genótipo determinado. Analisando a reação de cultivares de cevada suscetíveis e resistentes ao alumínio do solo, Eckert (1994) ressaltou a diminuição do índice mitótico para ambas as cultivares, apesar do resultado diferencial entre as mesmas. $\mathrm{O}$ índice mitótico mede, indiretamente, o crescimento de raízes de diversas plantas com relação a suas reações a metais pesados, como é o caso do trigo, comum e duro, do centeio e do triticale (Camargo et al., 1998).

Comparando todas as fases do ciclo celular dentro cada método de descongelamento, tanto da técnica de crioconservação sem o uso do crioprotetor como com o uso do crioprotetor, verificou-se que a frequência de células em prófase diferiu não só da interfase, mas também das demais fases da divisão celular (Pm, M, A e T), conforme a Tabela 5.

As células em prófase, crioconservadas sem o uso do crioprotetor e descongeladas em banho-maria, apresentaram frequência superior $(22,31 \%)$ aos demais métodos, o que também explica, de certa maneira, a diminuição de células em interfase com o conseqüente aumento do índice mitótico (27,40\%). Para aquelas crioprotegidas, a frequência de células em prófase foi maior para o descongelamento no ambiente $(12,99 \%)$, diferindo tanto da testemunha $(4,06 \%)$, como em microondas $(7,77 \%)$, relação esta que se inverte na interfase.

As fases da pró-metáfase, metáfase, anáfase e telófase não caracterizaram nenhuma das técnicas de crioconservação, nem os métodos de descongelamento, apresentando percentagens muito baixas, que variaram de $0,11 \%$, freqüência encontrada para células de ponta de raiz em metáfase obtidas de sementes criprotegidas e descongeladas em microondas, a 4,04\%, das células em pró-metáfase do material sem crioprotetor e descongelado em temperatura ambiente (Tabela $5)$.

Em trabalho realizado com inseticidas, que apresentam dois tipos diferentes de ingredientes ativos, Chauan et al. (1999) observaram que ambos inibiram a divisão mitótica e induziram quebras e aberrações cromossômicas em meristemas de raiz de cebola. Ao trabalhar com diferentes concentrações de nitrato de chumbo, Liu (1994) observou que o mesmo reduziu o crescimento de raízes e causou irregularidades mitóticas, como pontes anafásicas e cromossomos com aderências, em células de meristema de raiz de Allium cepa. A redução do crescimento de raízes foi devida à diminuição da freqüência de divisão celular produzida 
por este microelemento (ou metal pesado).

Resultados, em termos de índice mitótico, variam muito não só de espécie para espécie, mas também entre estudos realizados com a mesma espécie, devido a respostas diferenciais dos genótipos das cultivares utilizadas pelos pesquisadores. Isto mostra a importância do uso de sementes de mesmo genótipo e do estabelecimento de um tratamento controle/testemunha. Santiago e Cannen (1999) verificaram ser de $56,9 \%$ o índice mitótico de cebola.

\section{CONCLUSÕES}

A imersão em nitrogênio líquido, sem o uso de crioprotetor (glicerol 50\%), é uma técnica adequada para a crioconservação de sementes de cebola.

O tratamento criogênico, sem uso de crioprotetor (glicerol $50 \%$ ), não altera a germinação nem a composição química das sementes de cebola, sendo também o tratamento que apresenta maior número de células em divisão celular em todos os métodos de descongelamento estudados;

O tratamento criogênico, com uso de glicerol $50 \%$ como crioprotetor, é prejudicial à qualidade fisiológica e altera a composição química de sementes de cebola.

O método de descongelamento das sementes crioconservadas de cebola em microondas é mais adequado do que em temperatura ambiente e banho-maria, porém este último apresenta maior índice mitótico.

\section{REFERÊNCIAS}

ALBERTS, B.; JOHNSON, A.; LEWIS, J.; RAFF, M.; ROBERTS, K.; WALTER, P. Molecular Biology of the Cell. New York: Garland Science, 2002. p.1463.

ASSOCIATION OF OFFICIAL SEED ANALYSTS. Seed vigor testing handbook. East Lansing: AOSA, 1983. p.93 (Contribution, 32)

BRADFORD, M.M.. A rapid and sensitive method for the quantitation of microgram quantities of protein utilizing the pnnciple of dye binding. Analytical Biochemistry, n.72, p.248254,1976

BRASIL. Ministério da Agricultura e da Reforma Agrária. Regras para análise de sementes. Brasília: SNDA/DNDV/CLAV, 1992. $365 \mathrm{p}$.

CAMARGO, C.E.O; FERREIRA FILHO, A.W.P.; FREITAS, J.G. Avaliação de genótipos de centeio, triticale, trigo comum e trigo duro quanto a tolerância ao alumínio em solução nutritiva. Scientia Agricola, Piracicaba, v.55, n.2,1998.

CHANDEL, K.P.S.; CHAUDHURY, R.; RADHAMANI, J.; MALIK,
S.K. Desiccation and freezing sensitivity in recalcitrant seed of tea, cocoa and jackfruit. v. 76. New Delhi, India: NBPGR, 1995. p.443-450.

CHAUAN, L.K.S.; SAXENA, P.N.; GUPTA, S.K. Cytogenetic effects of cypermethrin and fenvalerate on the root meristem cells of Allium cepa. Environmental and Experimental Botany, Elmsford, v. 42, n.3, p.181-189, 1999.

CLEGG, K.M. The aplication of the anthrone reagent to the estimation of starch in cereals. Journal of the Science of Food and Agriculture, London, v.7, p.40-44, 1956.

COOPER, G.M. A Célula: uma abordagem molecular.Porto Alegre:Artmed, 2001.p.712.

DINIZ, P.S.C. Qualidade fisiológica das sementes de milho (Zea mays L.) submetidas a diferentes técnicas de crioconservação. 1999. 80f Dissertação (Mestrado),Universidade Federal da Paraíba, Campina Grande, 1999.

DUMET, D.; BENSON, E.E. The use of physical and biochemical sudies to elucicate and reduce cryopreservation-induced damage in hydrated/desiccated plant germplasm. In: ENGELMANN, F.; TAKAGI, H. (Ed.). Cryopreservation of tropical plant germplasm: current research progress and application. Japan International Research Center for Agricultural Science, Tsukuba, Japan: JIRCAS; Rome, Italy: IPGRI, 2000. p.43-56.

ECKERT, M.I. Efeito do alumínio tóxico na divisão celular em ponta de raiz de cevada (Hordeum vulyare L.). 1994. 42f. Dissertação (Mestrado em Agronomia) - Faculdade de Agronomia Eliseu Maciel, Universidade Federal de Pelotas, Pelotas,1994.

FLECK, R.A.; DAY, J.G.; CLARKE, K.J.; BENSON, E.E. CryoLetters, London, n.20, p.271-282, 1999.

GONZALEZ, R.A.F. Efeito da criopreservação usando técnicas de congelação e crioprotetores sobre parâmetros espermáticos e a integridade de membranas do espermatozóide bovino. Pirassununga: RAF, 2004. 92p.

HERRERA, I.L.; MATA, G., HERNÁNDEZ, R.G. Evaluation of the viability of pleurotus spp. strains after liquid nitrogen cryopreservation. Iberoam. Micol., Veracruz, México, n.15, p.4447, 1998 .

INTERNATIONAL BOARD FOR PLANT GENETIC RESOURCES. The desing of seed storage facilites for genetic conservation. Rome, 1982. p.95.

LIU, D.; JIANG, W.; WANG, W.; ZHAO, F.; LU, C. Effects of lead on root growth, cell division, and nucleolus of Allium cepa. Enviromental Pollution, v.86, n.1, p.1-4, 1994.

MARTÍNEZ-MONTERO, M.E.; MORA, N.; QUIÑONES, J.; GONZÁLEZ-ARNAO, M.T.; ENGELMANN, F.; LORENZO, J.C. Effect of cryopreservation on the structural and functional integrity of cell membranes of sugarcane (Saccharum sp.) embryogenic calluses. CryoLetters, London, n.23, p.237-244, 2002.

McCREADY, R.M.; GUGGOLZ, J.; WENS, H.S. Determination of starch and amylase in vegetables. Analytical Chemistry, Washington, v.22, p.1156-1158, 1950.

MEDEIROS, A.C.S.; CAVALLAR, D.A.N. Conservação de germoplasma de aroeira (Astronium urundeuva (Fr. All.) EngL). Revista Brasileira de Sementes, Brasília, v.14, n.1, p.713-75, 1992. 
PITA VILLAMIL, J. Crioconservación de semillas. In: CONGRESSO BRASILEIRO DE ENGE-NHARIAAGRÍCOLA, 26., 1997, Campina Grande, PB. Minicurso. Campina Grande:UFPB/SBEA, 1997. p.55.

ROOS, E.E.; STANWOOD, P.C. Effects of low temperature, cooling rate and moisture content on seed germination of lettuce. Journal of the American Society for Horticultural Science, Mount Vernon, n.106, p.30-34, 1981.

SAKAI, A. Cryopreservation of germplasm of woody plants. In: BAJAJ, Y.P.S. (Ed.) Biotechnology in agriculture and forestry. v.32. Cryopreservation of plant germplasm I. Berlin: SpringerVerlag; New York: Heiderlberg, 1995. p.53-69.

SALOMÃO, A.N. Respostas de sementes de espécies tropicais a exposição ao nitrogênio líquido. Brazilian Journal of Plant Physiology, Piracicaba, v.14, n.2, p.133-138, 2002.

SANTIAGO, F.I.; CANNEN, R.E.L. Mitotic index and chromosomal changes in Allium cepa as affected by an organophosphate pesticide, Malathion. Philippine Journal of Science, Manila, v.128, n.1, p.1, 1999.

SINGH, R.J. Plant cytogenetics. 2 ed. Boca Raton, USA: CRC, 2003. p.59-72.

SOARES, M.P.; ROSSI, C.A.R.; MEZZALIRA, A. Etileno glicol na criopreservação de sêmen canino. Ciência Rural, Santa Maria, v.32, n.4, p.649-655, 2002.

STANWOOD, P.C. Cryopreservation of seed germplasm for genetic conservation. In: . Cryopreservation of plant cell and organs. Boca Raton, Flórida: CRC, 1985. p.199-236.
STANWOOD, P.C. Survival of sesame (Sesamum indicum L.) seed at the temperature of liquid nitrogen $\left(-196^{\circ} \mathrm{C}\right)$. Crop Science, Madison, v.27, p.327-331, 1987.

STANWOOD, P.C. Tolerance of crop seeds to cooling and storage in Iiquid nitrogen $\left(-196^{\circ} \mathrm{C}\right)$. Journal of Seed Technology, Lincoln, n.5, p.26-31, 1980.

STANWOOD, P.C.; BASS, L.N. Seed germplasm preservation using liquid nitrogen. Seed Science and Technology, Zürich, v.9, p.423-437, 1981.

STANWOOD, P.C.; SOWA, S. Evaluation of onion (Allium cepa L.) seed after 10 years of storage at $5,-18$ and $-196^{\circ} \mathrm{C}$. Crop Science, Madison, v.35, p.852-856, 1995.

STONAYOVA, S.D. Seed storage for genetic conservation in the Bulgarian Genebank. In: Proceedings of a joint FAO/IPGRI workshop on ex situ germoplasm conservation, E. A. Frison and M. Bolton, (eds.). Rome, out. 1994.

VARGAS; D.P.; ROCHA, C.L.; ROCHA, B.H.G.; DODE, L.B.; BOBROWSKI, V.L. Efeito do glicerol como pré-condicionante na criopreservação de sementes de Origanum vulgare L. UCPel, 2004.

VIEIRA, M.L.C. Conservação de germoplasma in vitro. Biotecnologia, Ciência e Desenvolvimento, Brasília, v.3, n.14, p.1820,2000.

ZONTA, E.P.; MACHADO, A.D. SANEST: Sistema de Análise Estatística para Microcomputador. Pelotas: UFPel, 1984. 